\title{
Belief as a Cognitive and Practical Commitment
}

\author{
Sophie Djigo (Université Lille 3)
}

According to a certain picture of agency, action entails the agent's belief that he has a reason for acting. This does not mean, as Davidson or Williams would put it, that the agent, in order to be motivated to perform an action, needs to have a desire for $\mathrm{X}$ and the belief that doing $\phi$ is a means (maybe the best means) to reach the end $X$. Here, a belief is involved in the means/end deliberation of the rational agent, but this belief is in itself inert (independently from the motivational element which aims at a certain end). In the picture of agency I have in mind, action entails the agent's belief that he has a reason for acting insofar as this belief constitutes a cognitive and practical commitment expressing the agent's endorsement of his reason. Such a picture is to be found in Richard Moran's view [see: Moran 2001] in the context of the issue of selfknowledge.

For instance, Moran discusses the Sartrian case of the akratic gambler, and his analysis shows that, if the gambler takes his mental states to be mere objects independent from his own will and power, he won't be able to keep his decision to quit the game-tables. His own resolution to stop gambling will appear as another piece of empirical evidence, something that happened to him, but which is already a past attitude that he has no reason to preserve, as if it were not up to him to preserve (or remove) it. Moran's notion of belief is, like Stuart Hampshire's, an active attitude: "he [the agent] cannot regard it [his belief] as something that he happens to have, or as a fact about himself which he may deplore, but must accept" [Hampshire 1975, 86-87]. It seems that, in one sense, the akratic gambler has reasons to believe that he will not stop gambling, while in another sense, he has reasons for stopping gambling. However, his reasons for stopping gambling are also reasons to believe that he should act for these reasons and make up his mind in such a way.

Exploring the idea of a more practical relationship between the agent and his own mental life leaves room for reconsidering the relevance of the familiar analogy between reasons for belief and reasons for action. Even if their difference is usually admitted, insofar as epistemic reasons for belief are truthrelated, they are facts which constitute a case for (or against) the truth of a proposition whereas practical reasons for action are truth-independent and rather value-related, being facts which constitute some good or some point in performing the action for which they are reasons, they are also treated as equivalent, in the sense that the connection between reasons to believe and the 
corresponding belief would be analogous to the connection between reasons for action and the corresponding action.

In section \$1, I will briefly describe three conceptions of selfinterpretation involving very different accounts of the role of beliefs among other attitudes. In section $\S 2$, I will develop the importance of belief for the sensitivity to reasons, try to articulate the demand for realism and discuss the internalist requirement of motivational force expressed by Moran's concept of avowal or by Williams' thesis of reasons internalism. In section $\S 3$, the last section, I will try to point out the consequences of a conception of belief as a cognitive and practical commitment for the role of belief in action.

\section{Three conceptions of self-interpretation}

Saying that it is up to the agent to have an attitude whether or not to perform an action can be a misleading idea. In fact, the analogy between belief and action might let us think that we can decide what to believe, that we can "want" or intend to believe and then,-commence to believe at will, just like we can decide what to do, want to do something, etc... Such misinterpretation is to be found in Sydney Shoemaker's criticism on Moran, when he says that he is 'most doubtful [about the] parts of the book in which he develops the idea that it is essential to understanding self-knowledge that we see the subject as involved in such knowledge as an agent, and that one's knowledge of one's beliefs is in some way a manifestation of the fact that it is "up to him" what he believes' [Shoemaker 2003, 391].

In his own reply, Moran explains that there is confusion between the binding force of the agent's will and the cognitive constraints of his rationality. In fact, if some beliefs are "up to the agent", it is not because the agent can form them or revise them at will, but because he is engaged by evidence, reasons and justifications, that is, by cognitive commitments:

"There is much I agree with in these remarks, but I think it is assumed here that the only sense I could have in mind in speaking of believing something as 'up to me' is that of adopting a belief from sheer force of will, independent of evidence, reasons, or justification. But this is not what I mean. Rather, the sense of 'agency' I have in mind with respect to beliefs and other intentional states is specifically the agency that is engaged by evidence, reasons, and justification. If voluntarism is the view that beliefs and other states can be formed 'just like that', as an arbitrary act of will, then this view is not voluntaristic" [Moran 2003, 403].

There are three contrasting interpretations of self-knowledge and selfinterpretation: the first one is the perceptual model of self-observation, which has no room for agency, where the person is an empirical subject in a passive relationship to with her mental states; the second one is the voluntaristic view of an agent who arbitrary chooses his own attitudes and forms his mental life at 
will, independently of the constraints of the real world. In the first version, the agent has too weak a power whereas in the second version, he has too much power. The third version offered by Moran is that of an agent who consciously adopts his mental attitudes insofar as he has reasons to do so. In this last interpretation, one's mental state is not a pre-existing given, but a dynamic set of attitudes which might be revised and enlarged by the agent. Self-knowledge is thus not a matter of identification of mental items, but of the constitution of one's mental life and of resolution.

Indeed, the issue in Moran's view is not that of identifying one's attitudes, but of adopting an attitude; it is the question of how one comes to a belief (or another attitude...). The term "resolution" may suggest that having a belief is like performing an action: it is the result of the agent's deliberation and decision. In this sense, beliefs (and other intentional attitudes) would have a practical dimension and not (only) an epistemic one. We would come to a belief just as we come to perform an action. In order to clarify this point, I will first go back to the central role of belief in Moran's picture of agency and selfknowledge.

In his criticism of the voluntaristic implications of the constitutivist approach of self-knowledge, Moran opposes the understanding of selfknowledge in terms of arbitrary activities such as interpreting and describing, which can be pure acts of sheer will (think of interpreting oneself as guilty just as an exercise) and self-knowledge in terms of conscious beliefs about one's own mental life. Moran's concern is that a major specificity of the first-person relationship to oneself is the rational capacity not only to know one's mental state, but to change it (a power which cannot be extended in the same way to the other's mental life). The agent's prerogative to change his own attitudes shows something about the very nature of self-knowledge; roughly speaking, that it is not necessary passively constituted from the discovery of facts about oneself, and that it can be actively created by the agent himself, being a practical knowledge. In fact, two apparently contradictory aspects need to be reconciled in order to sketch an account of self-knowledge which includes a certain sense of activity of the subject and the asymmetry between first-person and thirdperson perspectives on one's mental life. The first aspect is the agent's causal power over his own attitudes and actions, that is, his capacity for selfdetermination [see: Korsgard 2009], in other words, "the "self-altering" character of certain self-interpretations" [Moran 2001, 54]. This must be articulated at the same time as the second aspect: the awareness of reasons to endorse specific attitudes, these reasons being independent from the agent's will and constituting the content of his attitudes. The latter aspect complies with a realistic requirement. If it is up to the agent to change his mind (who else would/could do it?), the reasons why he should change his mind are not up to him. 
Contrary to other activities or attitudes, the very concept of belief implies that we cannot resist the reasons to believe which are binding in the sense that the agent adheres to the content of his belief. If I have reasons to believe that $\mathrm{P}$, reasons I am aware of, I cannot but believe that $\mathrm{P}$.

\title{
2. Belief and the sensitivity to reasons
}

Belief is truth-related and needs to be justified by epistemic reasons which have a binding force. I've just evoked the famous case of akrasia. If we stick to what has been said above, one cannot have a (better) reason to believe something and fail to believe it, whereas one can have a (better) reason to do something and not do it. Reasons for belief are more powerful commitments, so that if practical akrasia is possible, epistemic akrasia is not, because it would involve resistance and indifference to truth and epistemic reasons. Hence, as Joseph Raz puts it,

\begin{abstract}
one who believes that there is a conclusive case for the truth of a proposition cannot but believe that proposition (pathological cases apart). There is no gap, no extra step in reasoning, between believing that the case for the truth of the proposition is conclusive and believing the proposition. Similarly, there is no gap between believing that the case for the truth of a proposition is inadequate and withholding belief in it. More directly and more generally (and again excepting pathologies), reasoning from (what we treat as) reasons for belief to a conclusion (from: "the door is open" to "therefore anyone could have walked in") we acquire the belief as we arrive at the conclusion. [Raz 2011, 36-58]
\end{abstract}

There is an understanding of belief which emphasizes its binding dimension as a cognitive and practical commitment, which explains Raz's affirmation that there is no gap between having reasons for a belief and adopting this belief (under certain conditions of rationality). I think that the pivotal role of belief in Moran's philosophy must be understood in the frame of this issue of sensitivity to reasons. Indeed, a person can perfectly be said to have a reason to desire, want, act...without adopting the corresponding attitude or revising a previous one in order to adjust his mental state to the world. It seems that there is an asymmetry between the way we come to adopt a belief for epistemic reasons we cannot resist, and the looser link between action and reasons for action. The notion of belief is meant to reinforce the link between reasons for belief and the consecutive adoption of one's attitude as appropriate.

The status of belief is central since belief is not an attitude among others (such as desires, intentions, etc...). In Self-Consciousness and Self-Determination, (Selbstbewusstsein und Selbstbestimmung), Ernst Tugendhat points out the fact that "the deliberative adoption of a position pertains in particular to the beliefs implied in one's own conceptions" [Tugendhat 1986, 254]. Every attitude involves a factual or a normative belief concerning this attitude, for instance, a desire for $\mathrm{X}$ implies the belief that $\mathrm{X}$ is desirable. The importance of belief lies in 
its implication in the activity of self-interpretation and in the constitution of self-knowledge. We need to distinguish cases where we speak of belief as a mere attitude among others, and cases where we consider belief insofar as it is involved in our other attitudes and actions.

Let us take the example of the emotion of fear: suppose that I interpret myself as fearing X. I might describe myself as fearing X without any reason, (and decide to fear $\mathrm{X}$ "at will" thus altering my emotional life without any reason, just because I want it); or for reasons provided by my considering my fear as an empirical fact. With the latter perspective, I can say that "I believe that I fear X", however strange it sounds, by reference to behavioural evidence and thus expressing a certain degree of uncertainty or doubts about myself. My reasons to believe that I fear X are provided by my inner or outer observations. With this sense of belief, self-interpretation refers to a theoretical stance towards oneself, to relying on evidential import, as if I were a spectator of my own mental life and offering a hypothesis about it. Again, belief about oneself in this sense involves an already constituted or objectified self. Furthermore, in this view; I have no power of altering or revising my emotion under the guidance of reason. In both cases, the notion of commitment is missing. There is, however, a second sense in which to understand belief according to which reasons for belief are justifying reasons provided by facts independent from the subject. This is this second sense which is present in Moran's conception of selfinterpretation as an active and practical modality of self-knowledge.

As he writes:

My fear was about something and dependent on my beliefs about that thing" and later, "if we can think of altering the interpretation or articulation of an emotion as involving a commitment akin to changing one's belief about it, and we view the emotion itself under its aspect as an attitude, we have something belief-like on both sides of the relation [Moran 2001, 54].

So believing that there are reasons to fear something leads me to fearing it. The content of belief is the reasons for (or against) attitudes and actions. Compare:

"I believe that I fear X" and "I believe that I am to fear X (that I should fear X, that I have reasons to fear X, that X is to be feared)"

Let us just recap: in the first sense, we have beliefs about ourselves, that is, beliefs about what we do think, what our own mental states, such as beliefs, desires, intentions, etc, are ...These are second-order attitudes. The reasons for believing that we have specific attitudes might be provided by psychological facts about oneself. In the second and more important sense, we have beliefs about what to think, what our mental states should be. The reasons to believe that we should adopt (change, revise,...) a particular attitude are justifying reasons which are provided by facts about the world. 
Now, we can understand why belief is not only a cognitive commitment, but also a practical one. Indeed, since beliefs are truth-related attitudes involving epistemic reasons, they constitute a cognitive commitment to the way things are. In addition, beliefs are tightly linked to the agent's resolution, that is, his capacity to make up his mind. The agent rationally decides to change his mind as far as he believes that he has reasons for doing so. His actual believing leads to his resolution, and in this sense, belief is also a practical commitment. The originality of Moran's placing of agency at the heart of self-knowledge is to think of the agent's relationship with his mental life in a practical and active way. Having an attitude means adopting an attitude, and this might be considered as an act. At the risk of exaggerating, we might say that intentional action is the model of the agent's relationship to his mental life and that, from a first-person's practical point of view, making up one's mind or changing one's mental states is an action or an activity. Just as action entails belief, a resolution to change one's attitude does too. That's why we need to look closer at the role of belief in action.

\section{Belief and its role in action}

The implication of belief in action has been much commented on in the past decades. The renewal of a kind of Humean model of the connection between belief and desire offers a description of intentional action as a result or an effect of a motivational element, the desire for a certain end, combined with the belief about the means to reach this end. In his famous essay, "Action, reasons and causes", Donald Davidson defends the view that an action is the effect of a mental causation involving a pro-attitude (desire) and an appropriate belief, both forming a "primary reason" for action which can be referred to in the context of a causal explanation of the action. The problem with such a view is that it suggests that beliefs are in themselves inert and that the agent needs something more to come to perform the action: a motivational element (proattitude). At the same time, the desire is an empirical and psychological fact which can only provide an explanatory reason for the action, and not a justifying one. The demand for justification is not offset by the association with a belief about the means/end connection and the sense of cognitive and practical commitment which has just emerged is lost.

Even if we stick to the internalist requirement for motivation, we can admit that belief is enough to motivate an action. This is something allowed, for instance, by Bernard Williams, when he says:

Does believing that a particular consideration is a reason to act in a particular way provide, or indeed constitute, a motivation to act? ... Let us grant that it does - this claim indeed seems plausible [Williams 1981, 107].

According to Williams, the motivating force of one's belief depends on a rational capacity to "conside[r] the matter aright" [Williams 1981, 109]. For the belief to 
play a role in action, it must be grounded in reasons to believe which the agent is aware of, and its content must provide a reason to perform the action. I think that the accent put on belief by Moran and other philosophers is meant to articulate precisely this internalist demand for motivational force which efficiently leads to the agent's resolution and the normative requirement for independent reasons which justify the action and preserve a realistic concern. In other words, the idea that belief is both a cognitive and a practical commitment is preserved and the notion of commitment or engagement is central to the conception of agency and of the agent's role in self-knowledge, and also to the very concept of rationality.

The specificity of belief is due to its twofold aspects, the cognitive one as a truth-value bearer and the practical one as a motivating element. Moreover, the fact that these two aspects are imbricated explains why the agent's belief may have a justifying role rather than a purely explanatory one. If reasons for belief and reasons for action or reasons for other attitudes are mostly treated as equivalent to one another, then the following striking passage found in Moran's account of belief leaves room for further analysis of the specificity of belief compared to action and other attitudes and for the role of belief in action:

As long as there are believers, and as long as beliefs purport to represent the world, it will be possible to ask of any belief both whether it is true or false, and how it disposes the believer to act. The two aspects of belief depend on each other, since the explanatory aspect requires an assumption of rationality, and that requires that the believer himself not treat his belief as an opaque psychological fact. In his awareness of his beliefs, he either acts upon them as he acts upon recognition of some aspect of the independent world, or he subjects them to revision [Moran 2001, 129-130].

If we follow Moran's view, the two different senses of belief we've distinguished above do not involve two concepts of belief, but rather "two interests in the same concept", the agent's first-person's interest and the spectator's thirdperson's interest. What the agent is interested in in the first place is the truth of his belief, while the interpreter is interested in the first place in the role of that belief in action, in order to reach a rationalizing explanation of the action. We need to distinguish the question of the truth of the agent's belief from the question of its role in his action, and to consider that in the agent's first-person's perspective, reasons for belief provide reasons for action, so that if his belief is false, such reasons will be explanatory, if it is true, they will be justifying.

From the agent's perspective, the question of truth of his beliefs is prior to the question of how they will dispose him to act. Beliefs "aim at truth" and do not enter into his practical reasoning in a way that brackets the question of their truth. The interpreter, on the other hand, will be interested in how beliefs explain behaviour, and this is a role played by false beliefs quite as often as true ones. Any 
representational state will have such a dual aspect, one under which it is treated as transparent to the world in a certain way, another under which it makes a contribution to the behaviour of the agent. Naturally, these different interests in belief are not restricted to the first-and third-person uses, respectively. In communicating and reasoning with others, for instance, we are concerned with the truth, and not just the explanatory adequacy, of the beliefs we take them to have; while, on the other hand, in understanding oneself, one will sometimes need to bracket the question of the truth of one's beliefs and concentrate on their explanatory role [Moran 2001, 130].

So, if beliefs play an explanatory role in action, can they play a justifying role too? Furthermore, can we treat reasons for belief and reasons for action as equivalent?

According to Moran, there is a difference to be made here since actions and intentions are the conclusions of practical deliberations about what to do or what to think, while beliefs are the conclusion of a theoretical deliberation about what the case is. This claim seems to be much weaker than the role played by belief in practical reasoning.

First, the content of beliefs is not restricted to "what is the case", but it might be extended to normative facts. Let us take an example and say that "I believe that the house is on fire". My belief is clearly about an empirical fact of the world and my reasons to believe are of an evidential nature, like the perception of smoke and flames. Whatever the truth of my belief, to be rational would be to respond to the reasons provided by my belief in the appropriate way: for instance, if I believe that the house is on fire, I have a good reason to jump into the canal. To follow Derek Parfit's analysis [see: Parfit 1997], we must take into account not only the facts which provide reasons to believe that the house is on fire (as a conclusion of theoretical deliberation about what the case is), but also the normative fact that (the fact that) the house is on fire gives me a reason to jump into the canal. Reasons for belief are different from reasons for action, but (i) epistemic reasons for belief might provide practical reasons for action and (ii) reasons for belief might provide normative reasons for action (explanatory reasons when the belief is false; justifying reasons when the belief is true).

Hence the second problematic aspect: under normal conditions of rationality, the agent's resolution is an appropriate response to his belief (and therefore, to the world since his belief is about how things are). This sense of appropriateness, as in William's "considering the matter aright" or in Korsgaard's reference to the "right way", refers to a certain notion of normativity. So, even if, as Moran says, it is true that "from the agent's perspective, the question of truth of his beliefs is prior to the question of how they will dispose him to act", the question of the appropriateness of action as a response to the agent's belief is still of great significance. This corresponds to 
the picture of the deliberating agent who forms his beliefs on the basis of reasons provided by the world, and who acts according to his beliefs and thus; endorses normative reasons about appropriateness. The way our beliefs dispose us to act implies a kind of redoubled belief: belief about the facts in the world and belief about how these facts provide reasons for a specific action or resolution.

\section{Conclusion}

I will end with a few remarks on the limits of the account of belief as a cognitive and practical commitment that I've tried to sketch in this paper.

Firstly, I have considered beliefs as truth-related attitudes, grounded in epistemic reasons. However, if we stick to our idea that beliefs are practical as well as cognitive commitments, we must admit that reasons for belief might sometimes be practical rather than epistemic reasons. This point, underlined for instance by Joseph Raz, means that the agent's reasons to believe a particular proposition might be independent from the truth of the belief. Raz calls them "practical" non-standard reasons for belief, and he offers an example:

For example, imagine that someone promises Jake a large sum of money if he believes that $P$. By all accounts this is a reason to have a belief. I claim that it is a non-standard reason for it cannot be followed [Raz 2011, 53].

In such a case, the agent does not commit himself to the truth of the proposition, but shall we consider that he has a practical commitment or on the contrary, that any sense of commitment has been lost here? The agent might as well have such a practical reason to believe that $\mathrm{P}$ without coming to form this belief. We have lost the binding force of the reasons for belief, so that there is a gap between having reasons to believe that $\mathrm{P}$ and believing that $\mathrm{P}$. Moreover, the fact that this practical reason cannot be followed indicates that the agent's relationship to his belief has lost the characteristic of transparency which was specific to the avowal of one's belief from the first-person perspective. The sense of commitment has disappeared.

Secondly, the example shows that the idea of the agent's avowal of his own attitudes, and his awareness of his reasons to adopt (change, keep) such attitudes must not be misunderstood: it does not mean that the agent's reasons are subjective, that they only depend on his understanding of the situation. The avowal of one's attitude, as well as the resolution to adopt an attitude or to perform an action implies the agent's rational consideration of normativity, that is, that the agent should know what provides him with a reason and what this reason can be a reason for ${ }^{1}$.

\footnotetext{
${ }^{1}$ See Raz's distinction between standard and non-standard reasons.
} 
Thirdly, according to Raz, our direct way of responding to practical (nonstandard) reasons for believing something is by an action, and not the formation of a belief. The revision of the belief is an indirect response, conditioned by the antecedent action. In the case of a practical reason to believe something, we can change our mental state in order to conform to the belief instead of conforming our belief to how things are. Therefore, practical non-standard reasons for belief might be standard reasons for action with a real normative force. Thus, "a nonstandard reason to believe that $\mathrm{P}$ is a standard reason to bring it about that $\mathrm{I}$ believe that P" [Raz 2011, 57]. In this case, the agent's belief does not rely on any conviction provided by a theoretical deliberation, and his priority is not the truth of his belief. He seems to be in the position described by Moran where "I may reason my way to a conclusion about what to do that leaves me the further task of somehow managing to commit myself to it" [Moran 2001, 132]. The agent here is trying to produce results in himself, to cause his own state of belief. What is the difference between that and his power of self-determination of his own mental life?

Again, the difference is the difference between the points of view and relationships toward oneself. In the case depicted by Raz, the agent takes his practical (non-standard) reason to believe that $\mathrm{P}$ as an explanatory one, something he cannot avow nor adopt with conviction. It is rather a case of selfdeception. However, his belief might be the conclusion of a certain reasoning, not a deliberation whose conclusion would be a belief, but a practical deliberation whose conclusion is an act in order to reach the belief afterward through a kind of self-manipulation. This example provides an illuminating contrast to Moran's account of agency and to his conception of the role of belief in action from a first-person perspective.

\section{Literature}

Hampshire, S. 1975. Freedom of the Individual. Princeton: Princeton University Press.

Korsgaard, Ch. 2009. Self-Constitution: Agency, Identity, and Integrity. Oxford: Oxford University Press.

Moran, R. 2001. Authority and Estrangement. An Essay on Self-Knowledge. Princeton: Princeton University Press.

- 2003. "Responses to O'Brien and Shoemaker". European Journal of Philosophy Vol. 11: 402-419.

Parfit, D. 1997. "Reasons and Motivation". Proceedings of the Aristotelian Society - Supplementary Volumes Vol. 71: 99-146.

Raz, J. 2011. "Reasons: Practical and Adaptive". In: Raz, J. From Responsibility to Normativity. Oxford: Oxford University Press: 36-58.

Shoemaker, S. 2003. "Moran on Self-knowledge". European Journal of Philosophy Vol. 11: 391-401. 
Tugendhat, E. 1986. Self-Consciousness and Self-Determination. Trans. Paul Stern. Cambridge: MIT Press.

Williams, B. 1981. "Internal and External Reasons". In: Williams, B. Moral Luck. Cambridge: Cambridge University Press. 
Sophie Djigo (Université Lille 3)

\title{
Belief as a Cognitive and Practical Commitment
}

\begin{abstract}
Exploring the idea of a more practical relationship between the agent and his own mental life leaves room for reconsidering the relevance of the familiar analogy between reasons for belief and reasons for action. Even if their difference is usually admitted, they are also treated as equivalent, in the sense that the connection between reasons to believe and the arising belief would be analogous to the connection between reasons for action and the arising action. If such an analogy might be relevant to a certain extent in the frame of a theoretical stance towards oneself, I'll argue that it cannot be maintained once we have put the agent at the heart of self-knowledge.
\end{abstract}

Keywords: agency. belief, practical knowledge, reasons, self-interpretation

Ethics in Progress (ISSN 2084-9257). Vol. 4 (2013). No. 2. pp. 34-45. 